\title{
Transformation of the TiNi Alloy Microstructure and the Mechanical Properties Caused by Repeated B2-B19' Martensitic Transformations
}

\author{
Anna Churakova ${ }^{1,2} \cdot$ Dmitry Gunderov $^{1,2} \cdot$ Alexander Lukyanov $^{2} \cdot$ Niklas Nollmann $^{3}$
}

Received: 25 March 2015/Revised: 1 September 2015/Published online: 12 October 2015

(C) The Chinese Society for Metals and Springer-Verlag Berlin Heidelberg 2015

\begin{abstract}
The influences of thermal cycling treatment in the temperature range of B2-B19 martensitic transformations $\left(-150\right.$ to $\left.150{ }^{\circ} \mathrm{C}\right)$ on the TiNi alloy structure and properties were studied. Different states named the initial coarse-grained (CG) state, the ultrafine-grained (UFG) state after ECAP (with a grain size of $200 \mathrm{~nm}$ ), the state after ECAP and cold upsetting by $30 \%$ were considered. The results show that the microhardness and the strength increase in all the three states. According to the XRD analysis, a more significant increment in the dislocation density, resulting from thermal cycling, is observed in the UFG alloy than in the CG alloy.
\end{abstract}

KEY WORDS: Thermal cycling; TiNi alloy; Equal-channel angular pressing; Martensitic transformation

\section{Introduction}

TiNi-based alloys belong to the class of functional materials with a shape memory effect (SME) caused by the thermoelastic martensitic transformations [1-4]. These alloys are widely used as the structural functional materials in engineering and medicine. Processing of ultrafinegrained (UFG) and nanocrystalline (NC) states by severe plastic deformation techniques' service properties makes increase for different metals and alloys, including TiNibased alloys [5, 6]. The two most popular SPD techniques are high-pressure torsion (HPT) and equal-channel angular

Available online at http://link.springer.com/journal/40195

Anna Churakova

churakovaa_a@mail.ru

1 Institute of Molecule and Crystal Physics RAS, 151 pr. Oktyabrya, Ufa 450075, Russia

2 Ufa State Aviation Technical University, 12 K. Marx street, Ufa 450000, Russia

3 Institute of Materials Physics, University of Münster, Wilhelm-Klemm Street10, 48149 Münster, Germany pressing (ECAP) [5]. The ECAP technique enables to produce large-sized samples with a grain size of about $300 \mathrm{~nm}$, and strength and shape memory effect property enhance. The HPT technique enables to produce TiNi samples in the amorphized state, and their subsequent annealing may result in the formation of an NC structure with a grain size starting from $20 \mathrm{~nm}$ [6]. Studies have shown that TiNi alloys in the NC state with a grain size of about $50 \mathrm{~nm}$ demonstrate the highest service properties [6]. UFG TiNi and NC TiNi are of great interest for practical applications $[5,7,8]$.

Thermal cycling (TC) is a technique used for additional enhancement of strength properties in some alloys. The term "thermoelastic transformation" in the strict sense excludes any noticeable irreversible changes. However, in the case of coarse-grained (CG) $\mathrm{TiNi}$, the increase in the dislocation density takes place during multiple cycles of martensitic transformations, which is accompanied by a slight change in the martensitic transformation temperature and some enhancement of the yield stress during mechanical loading. But "phase hardening" resulting from thermal cycling of CG TiNi is not considerable [9]. The materials in the UFG and $\mathrm{NC}$ states are characterized by an enhanced specific surface area of the grains $(\mathrm{S})$. The influence of the grain boundaries 
on defect generation during cyclic martensitic transformations is poorly studied at present. Unlike the majority of other known materials with martensitic transformations (steels, etc.), the temperatures of martensitic transformations in TiNi are close to the room one, that is why thermal cycling does not lead to recrystallization of UFG and NC structures [10]. In this connection, TiNi is an interesting object to study the effects of the UFG and NC states, the grain size and increased area of the grain boundaries on phase hardening resulting from thermal cycling. Grain boundaries as crystalline lattice defects can be the centers for dislocation nucleation during martensitic transformation, and therefore, phase hardening during thermal cycling in UFG TiNi can intensify. On the other hand, in UFG TiNi, martensite plates are limited within a single grain. Thus, in UFG TiNi, the sizes of martensite plates are smaller, which may reduce internal stresses during the growth of martensite plates. In this connection, the intensity of dislocation generation during a cycle of martensitic transformations in a UFG material may decline. It is of special interest to establish the influence of the UFG state of TiNi alloys on the structural changes during thermal cycling through martensitic transformation temperatures, determine the role of the grain boundaries in dislocation generation at phase martensitic transformations, and establish the possibility of enhancement of the mechanical and functional properties of these materials via phase hardening. There are a limited number of publications reporting on the studies of the effect of thermal cycling on UFG TiNi alloys [11-13]. The paper of Tong et al. [11] is devoted mainly to the effect of mechanocycling on the superelastic deformation of ECAP-processed TiNi. The studies of Babicheva et al. [12,13] mainly deal with the issues of dilatation in UFG TiNi alloys during thermal cycling.

This study presented the effect of the thermal cycling treatment in the temperature range of -150 to $150{ }^{\circ} \mathrm{C}$ of TiNi alloy under different states on the structures and properties.

\section{Materials and Methods}

The studies were carried out on $\mathrm{Ti}_{49.3} \mathrm{Ni}_{50.7}$ (at\%) alloy (manufactured by CJSC, Industrial Center MATEX, Moscow) subjected to homogenizing water quenching from $800{ }^{\circ} \mathrm{C}$. The alloy is in the austenite state with a B2 structure $(\mathrm{CzCl}$ type $)$ at room temperature.

In order to form a UFG state, quenched cylinder samples ( $\varnothing 20 \mathrm{~mm}$, length $100 \mathrm{~mm}$ ) were subjected to 8 passes of ECAP using a die-set with the angle of channels' intersection of $120^{\circ}$ at $450{ }^{\circ} \mathrm{C}$.

Separated samples after ECAP were subjected to additional deformation by cold upsetting by $30 \%$ producing a
UFG state with enhanced dislocation density and shear bands.

Thermal cycling treatment of the samples in different initial states was carried out by cooling to the temperature of liquid nitrogen $\left(-196{ }^{\circ} \mathrm{C}\right)$ and heating to $150{ }^{\circ} \mathrm{C}$, which is a priori lower and higher than the temperatures of direct $\mathrm{M}_{\mathrm{f}}$ and reverse $\mathrm{A}_{\mathrm{f}}$ martensitic transformations $\left(M_{\mathrm{f}}\right.$ and $\left.A_{\mathrm{f}}\right)$. The number of "heating-cooling" thermal cycles was from 0 to 100 . The holding time at the heating and cooling temperatures was $3 \mathrm{~min}$.

Calorimetric testing of the material was performed on a Diamond Pyris (Perkin Elmer) differential calorimeter. In order to analyze the martensitic transformation temperatures, differential scanning calorimetry (DSC) was performed on the samples with a diameter of $4.5 \mathrm{~mm}$ and a thickness of $0.5 \mathrm{~mm}$ in the temperature range from -150 to $150{ }^{\circ} \mathrm{C}$. The heating and cooling rate was $20^{\circ} \mathrm{C} / \mathrm{min}$. The characteristic temperatures of the martensitic transformations for this alloy in the quenched state are $M_{\mathrm{s}}=-32{ }^{\circ} \mathrm{C}$, $M_{\mathrm{f}}=-62{ }^{\circ} \mathrm{C}, A_{\mathrm{s}}=-29^{\circ} \mathrm{C}, A_{\mathrm{f}}=-5^{\circ} \mathrm{C}$.

The fine structure of the material was studied by a JEM2100 transmission electron microscope (TEM) at an accelerating voltage of $200 \mathrm{kV}$. The foils for electron microscopic studies were prepared on a TenuPol-5 twin-jet electropolishing set according to the standard procedure with the help of the electrolyte $10 \% \quad \mathrm{HClO}_{4}+90 \%$ $\mathrm{CH}_{3}\left(\mathrm{CH}_{2}\right)_{3} \mathrm{OH}$ (90\% butanol). The voltage was $50 \mathrm{~V}$. Tensile tests were performed at room temperature with a test speed of $10^{-3} \mathrm{~s}^{-1}$ on a tensile machine designed at USATU.

The quantitative studies of the structural parameters were carried out using X-Ray diffraction peak profile analysis (XDPPA). X-ray diffraction patterns were obtained on a Rigaku Ultima IV diffractometer in the range of $2 \theta$ from $30^{\circ}$ to $120^{\circ}$. The dislocation density and other parameters were determined via the procedure described in $[14,15]$.

\section{Results and Discussion}

In the initial CG state at the room temperature, the $\mathrm{Ti}_{49.3} \mathrm{Ni}_{50.7}$ alloy has an austenitic structure with a grain size of about $(50 \pm 5) \mu \mathrm{m}$ according to optical metallography analysis (Fig. 1a). Optical metallography does not allow performing precision estimation of the structural changes after thermal cycling (Fig. 1b). According to the TEM, dislocation-free grain boundaries are observed in the CG state (Fig. 1c). After thermal cycling with a number of cycles equal to 20 , the dislocations pile up near the grain boundaries due to phase hardening (Fig. 1d).

The subsequent increase in the number of the thermal cycles to 100 has apparently resulted in an additional 

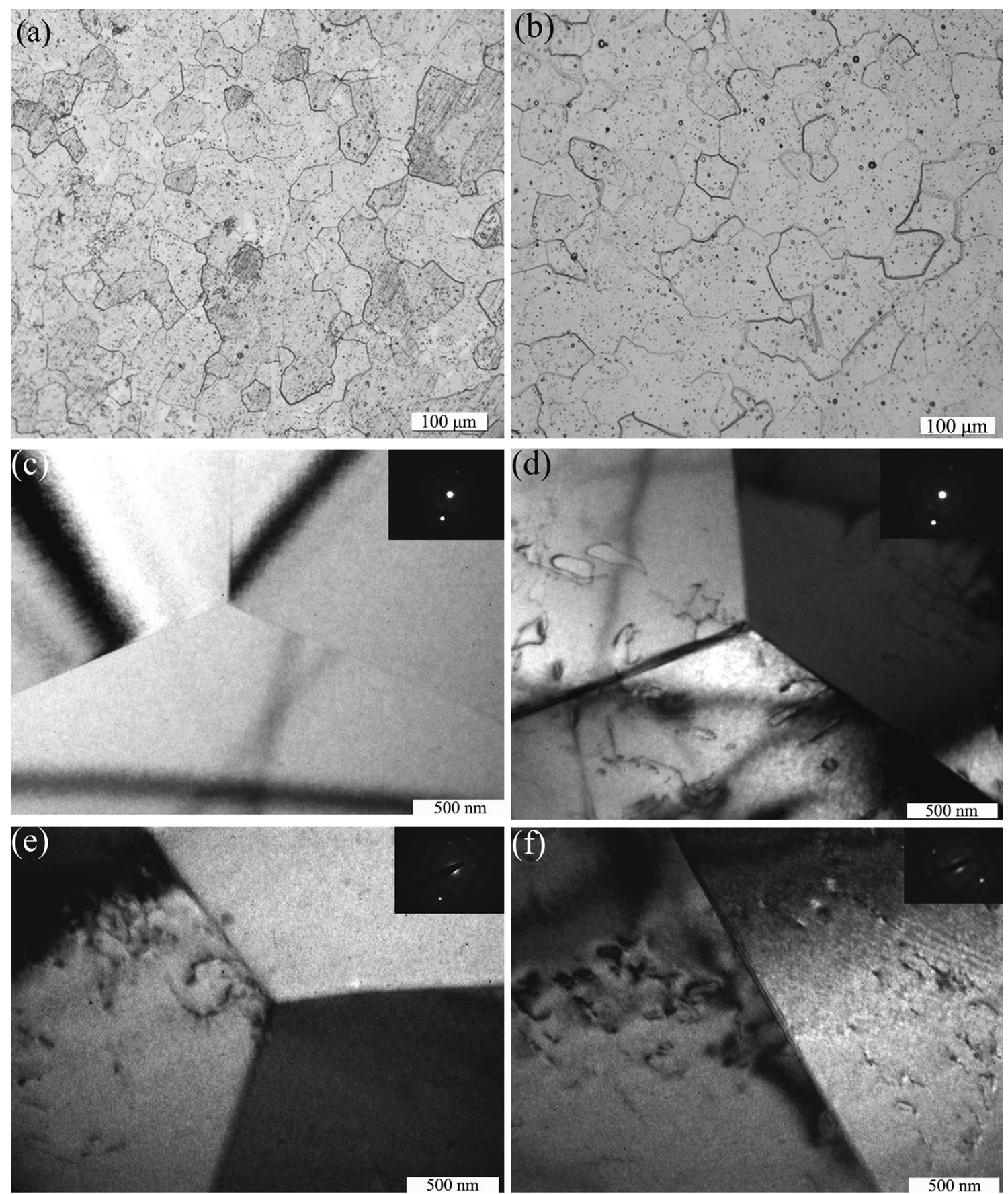

Fig. 1 Structures of $\mathrm{Ti}_{49.3} \mathrm{Ni}_{50.7}$ in different states: a CG, b CG + TC $(\mathrm{OM}), \mathbf{c}$ CG $(\mathrm{TEM}), \mathbf{d} \mathrm{CG}+\mathrm{TC}(n=20)$, e CG $+\mathrm{TC}(n=50)$, f CG + TC $(n=100)$

increase in the dislocation density in the grains body, near the grain boundaries and triple joints (Fig. 1 e, f).

After ECAP processing, a UFG structure with a grain size of about $200 \mathrm{~nm}$ is formed in TiNi (Fig. 2a). As the result of thermal cycling increase to 20,50 and 100, the dislocation density increases apparently as shown in (Fig. 2b, c, d).

Cold upsetting by $30 \%$ of an ECAP-processed sample usually leads to the formation of deformation bands and a significant increase in the dislocation density in the structure. The bandwidth and the size of structural elements are about $50 \mathrm{~nm}$ (Fig. 3a). Thermal cycling leads to the increase in the dislocation density in some separated structure areas (Fig. 3b); however, the TEM method did not show quantitative changes in the structure with an increasing number of cycles from 50 to 100 (Fig. 3c, d).

As is reasonably expected (Table 1), the values of peak broadening and dislocation density in UFG alloy are 

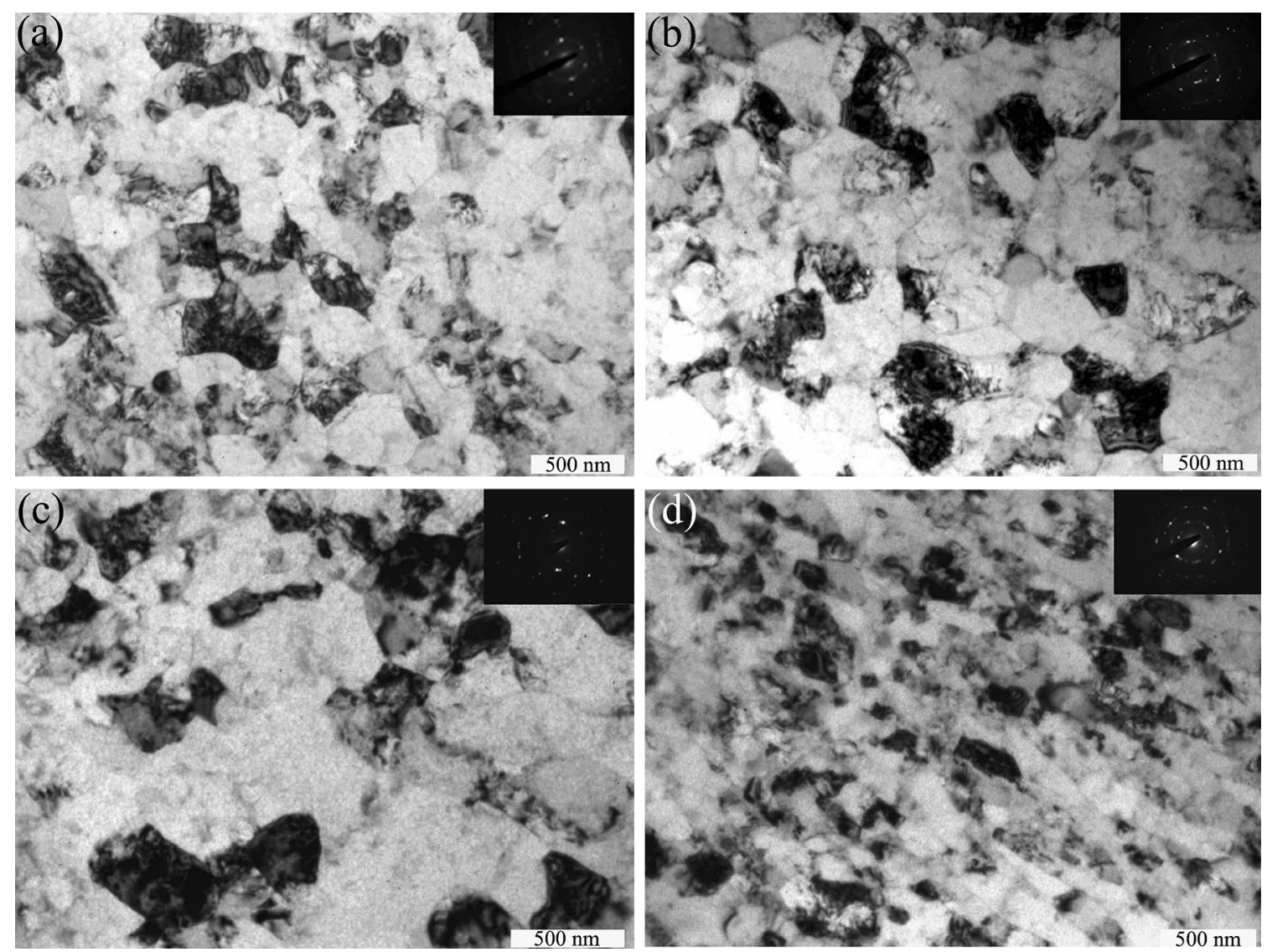

Fig. 2 Microstructures of $\mathrm{Ti}_{49.3} \mathrm{Ni}_{50.7}$ in the UFG state: a UFG, b UFG + TC $(n=20)$, $\mathbf{c}$ UFG + TC $(n=50), \mathbf{d}$ UFG + TC $(n=100)$

notably higher, and the CSR size is markedly smaller, than those in CG TiNi. In the state UFG + upsetting (Table 1), the values of peak broadening and dislocation density are visibly higher than those in the UFG alloy.

The values of peak broadening and dislocation density in the CG TiNi alloy slightly grow, while the CSR dimensions slightly decrease, as a result of thermal cycling. A similar increment in peak broadening has been observed earlier, as a result of the thermal cycling of the $\mathrm{CG} \mathrm{TiNi}_{50.7}$ alloy [17].

The analysis of the XRD data (Table 1) demonstrates that in the UFG alloy the values of peak broadening grow more significantly as a result of thermal cycling than those in the CG TiNi alloy. The increment in the dislocation density, resulting from thermal cycling, was $\Delta \rho \approx 1 \times 10^{15} \mathrm{~m}^{-2}$ in the CG alloy and $\Delta \rho=3.7 \times 10^{15} \mathrm{~m}^{-2}$ in the UFG alloy. An even larger increment in the dislocation density, resulting from thermal cycling, is observed in the UFG + upsetting alloy $-\Delta$ $\rho \approx 6.2 \times 10^{15} \mathrm{~m}^{-2}$. Therefore, a conclusion can be made that the high density of the grain boundaries and dislocations, both for the states of UFG and UFG + upsetting, contributes to the intensification of phase hardening (dislocation density enhancement) during thermal cycling (Fig. 4).

The dimensions of coherent scattering regions in CG TiNi significantly decrease as a result of thermal cycling.
In the UFG and UFG + upsetting alloys, the dimensions of CSR also decrease as a result of thermal cycling, but not so much is in CG TiNi. Table 2 shows the results of the studies on the martensitic transformation temperatures, performed by DSC.

The analysis of calorimetric data allows making a conclusion that the thermal cycling results in an increase in the martensitic transformation temperatures, especially $M_{\mathrm{s}}$ and $M_{\mathrm{f}}$. The most significant increases in the temperatures $M_{\mathrm{s}}$ and $M_{\mathrm{f}}$ are observed for the UFG state (by $50{ }^{\circ} \mathrm{C}$ and $35{ }^{\circ} \mathrm{C}$, respectively), whereas in the $\mathrm{CG}$ state the temperatures $M_{\mathrm{s}}$ and $M_{\mathrm{f}}$ increase approximately to $25{ }^{\circ} \mathrm{C}$. In the UFG alloy, as a result of $\mathrm{TC}$, the $A_{\mathrm{f}}$ temperature also increases significantly $\left(29^{\circ} \mathrm{C}\right)$. At the same time, in the CG alloy, the temperatures $A_{\mathrm{s}}, A_{\mathrm{f}}$ change insignificantly as a result of TC. It has been shown earlier in some papers $[4,16]$ that during thermal cycling of CG TiNi the martensitic transformation temperatures $M_{\mathrm{s}}$ and $M_{\mathrm{f}}$ slightly decrease. According to our investigations, the martensitic transformation temperature increases in TiNi as a result of TC. This can be conditioned by alloy aging due to the used thermal cycling regimes or by intermediate R-transformation. This phenomenon requires additional studies. 

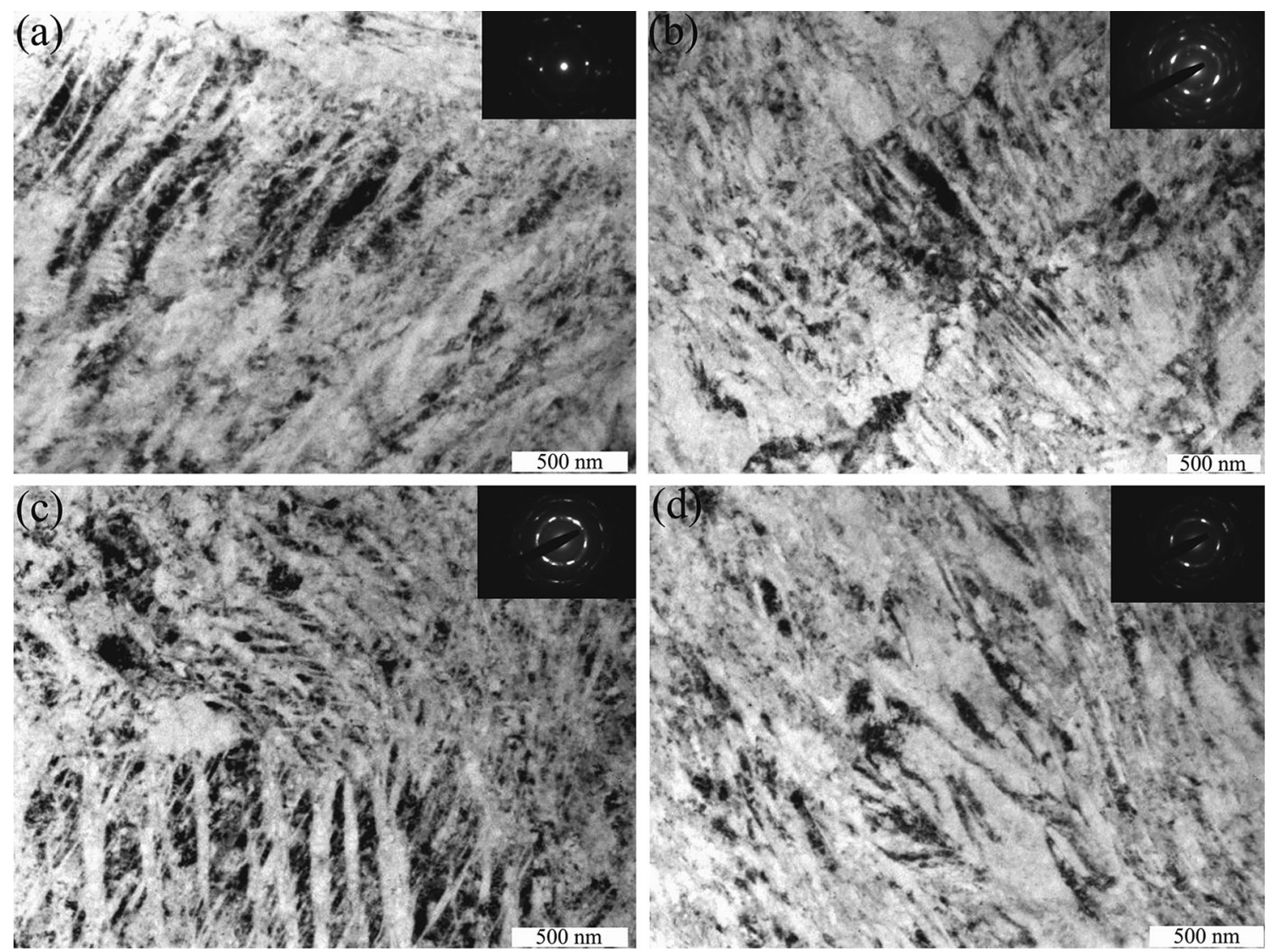

Fig. 3 Structures of $\mathrm{Ti}_{49.3} \mathrm{Ni}_{50.7}$ : a ECAP + cold upsetting, b ECAP + cold upsetting and TC $(n=20)$, c ECAP + cold upsetting and TC $(n=50), \mathbf{d}$ ECAP + cold upsetting and TC $(n=100)$

Table 1 Parameters of the $\mathrm{Ti}_{49.3} \mathrm{Ni}_{50.7}$ structure according to $\mathrm{X}$-ray analysis

\begin{tabular}{llccc}
\hline State & FWHM $(110)$ & CSR $(\mathrm{nm})$ & $E(\%)$ & $\rho \times 10^{15}\left(\mathrm{~m}^{-2}\right)$ \\
\hline CG & 0.282 & 158 & 0.122 & 0.8 \\
CG + TC & 0.347 & 49 & 0.221 & 1.8 \\
$\Delta$ & 0.065 & 109 & 0.099 & 1 \\
UFG & 0.327 & 43 & 0.250 & 5.8 \\
UFG + TC & 0.440 & 40 & 0.465 & 9.6 \\
$\Delta$ & 0.113 & 3 & 0.215 & 3.8 \\
UFG + upsetting & 0.96 & 31 & 0.647 & 16 \\
UFG + upsetting + TC & 1.13 & 27 & 0.854 & 22 \\
$\Delta$ & 0.17 & 4 & 0.207 & 6.2 \\
\hline
\end{tabular}

FWHM is X-ray peak broadening; CSR is coherent scattering regions, nm; $E$ is root-mean-square microdistortions, $\%$; $\rho \times 10^{15}$ is dislocation density, $\mathrm{m}^{-2} ; \Delta$ is the difference in the corresponding parameters prior to and after thermal cycling

The DSC technique did not allow determining the martensitic transformation temperatures in the states $\mathrm{UFG}+$ upsetting and UFG + upsetting + TC. However, TC leads to growth of the microhardness and the dislocation density in the UFG + upsetting state. Consequently, the martensitic transformations take place in this state as well. Perhaps, in the UFG + upsetting state, the sample has microstructure inhomogeneity. Therefore, in different areas of the sample, transformations take place at different temperatures, and as a result, separated transformation peaks are not determined by DSC.

The microhardness $H_{\mathrm{V}}$ of the $\mathrm{Ti}_{49.3} \mathrm{Ni}_{50.7}$ alloy in all the studied states increases as a result of thermal cycling as compared to the initial state (Fig. 5).

The microhardness $H_{\mathrm{V}}$ increases monotonously at the CG and UFG states with the number of cycles from 0 to 


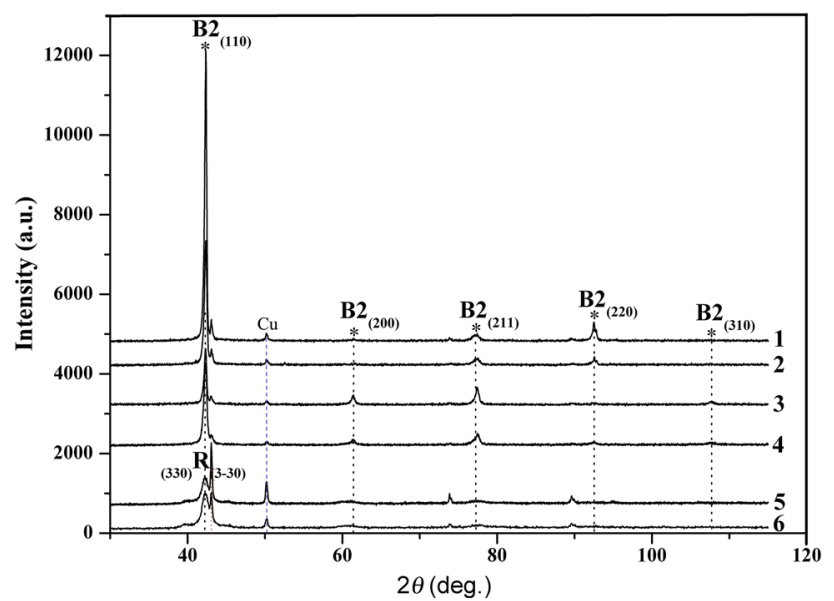

Fig. 4 X-ray diffraction patterns of the alloy $\mathrm{Ti}_{49.3} \mathrm{Ni}_{50.7}: 1 \mathrm{CG}, 2$ $\mathrm{CG}+\mathrm{TC} ; 3 \mathrm{UFG}, 4 \mathrm{UFG}+\mathrm{TC} ; 5 \mathrm{UFG}+$ cold upsetting, 6 $\mathrm{UFG}+$ cold upsetting $+\mathrm{TC}$

Table 2 Characteristic temperatures of martensitic transformations

\begin{tabular}{lrlllll}
\hline State & \multicolumn{1}{c}{$M_{\mathrm{s}}$} & $M_{\mathrm{f}}$ & \multicolumn{1}{c}{$A_{\mathrm{s}}$} & $A_{\mathrm{f}}$ & $M_{\mathrm{s}}-M_{\mathrm{f}}$ & $A_{\mathrm{s}}-A_{\mathrm{f}}$ \\
\hline $\mathrm{CG}$ & -32 & -62 & -29 & -5 & 30 & 24 \\
$\mathrm{CG}+\mathrm{TC}^{*}$ & -6 & -41 & -39 & -2 & 35 & 37 \\
$\mathrm{UFG}$ & -23 & -47 & -11 & 3 & 24 & 14 \\
$\mathrm{UFG}+\mathrm{TC}^{*}$ & 27 & -12 & -3 & 32 & 39 & 35 \\
\hline
\end{tabular}

* Thermal cycling $n=100 . M_{\mathrm{s}}$ is martensitic transformation start temperature; $M_{\mathrm{f}}$ is martensitic transformation finish temperature; $A_{\mathrm{s}}$ is reverse transformation start temperature; $A_{\mathrm{f}}$ is reverse transformation finish temperature

100. As for the UFG + upsetting state, the microhardness grows intensively during the first 20 cycles and is followed by saturation with a further increase in the number of cycles to 100. But the microhardness increment during the thermal cycling of the UFG state after upsetting is higher than that in the UFG and CG states (Fig. 5, Table 3).

As shown in Fig. 6, the ultimate tensile strength $\sigma_{\mathrm{B}}$ of $\mathrm{Ti}_{49.3} \mathrm{Ni}_{50.7}$ in the CG state is $820 \mathrm{MPa}$ and increases to $900 \mathrm{MPa}$ as a result of thermal cycling due to phase hardening. Deformation-induced martensitic transformation as a phase pseudo-yield plateau typically of the CG state is observed on the plots. The values of the stress of deformation-induced martensitic transformation (phase yield stress $\sigma_{\mathrm{m}}$ ) also grow as a result of thermal cycling, from 440 to $620 \mathrm{MPa}$. This is accounted by the fact that the dislocations in the austenite phase, which formed as a result of thermal cycling, hamper deformation-induced martensitic transformation. Note should be made that the stress of dislocation flow (YS) of the CG alloy is very close to the value of $\sigma_{\mathrm{m}}$. In this connection, the YS value of the CG alloy and its increment resulting from TC are difficult to be determined precisely. However, according to our

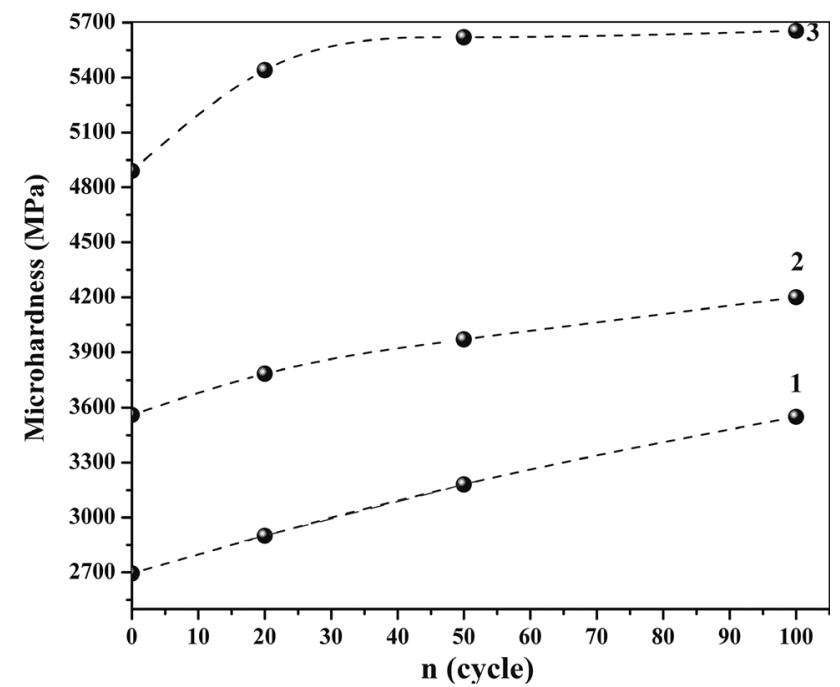

Fig. 5 Microhardness plots under different states (1 CG, 2 UFG, 3 UFG + cold upsetting)

estimation, the YS of the CG alloy has increased by $100 \mathrm{MPa}$ as a result of TC (note should be made that in the paper [17] an approximately proportional increment was observed in the YS of the CG $\mathrm{TiNi}_{50.7}$ alloy as a result of TC, $n=50$ ), but the ductility of the CG alloy was reduced from 36 to $31 \%$ a result of thermal cycling.

The ultimate tensile strength value (1310 MPa) and the yield stress value (1130 MPa) of the UFG alloy are significantly higher than those of the CG alloy (820 and $520 \mathrm{MPa}$, respectively). At the same time, the phase yield stress values $\left(\sigma_{\mathrm{m}}\right)$ of the UFG alloy and the CG alloy are almost identical (450 and $440 \mathrm{MPa}$, respectively). Thus, the formation of a UFG structure with an increased density of the grain boundaries efficiently increases the yield stress of the alloy, but has little effect on the phase yield stress values. Thermal cycling insignificantly increases the UTS and YS of the UFG alloy to $1360 \mathrm{MPa}$ and $1200 \mathrm{MPa}$ (Table 3). The increments in the ultimate tensile strength and YS of the UFG alloy, resulting from thermal cycling, are even somewhat smaller than those in the CG alloy. At the same time, in the UFG alloy, the dislocation density grows more significantly, as a result of thermal cycling, than that in CG TiNi (Table 3). Perhaps, the small increment in the UTS and YS of the UFG alloy, resulting from thermal cycling, can be accounted for by the fact that the UFG alloy is already in a strengthened state. The phase yield stress values of the UFG alloy also grow as a result of thermal cycling (Table 3 ).

In the UFG + upsetting state, the ultimate tensile strength was about $1750 \mathrm{MPa}$, which is noticeably higher than that in the UFG state. It should be noted that the curve rate for the state with a high density of defects differs from those of the CG and UFG states. There is no phase pseudoyield plateau on the curves for the UFG + upsetting alloy, 
Table 3 Results of mechanical tensile tests of $\mathrm{Ti}_{49.3} \mathrm{Ni}_{50.7}$ in different states

\begin{tabular}{|c|c|c|c|c|c|}
\hline State & UTS (MPa) & $\sigma_{\mathrm{m}}(\mathrm{MPa})$ & $Y S(\mathrm{MPa})$ & $\delta(\%)$ & $\mathrm{HV}(\mathrm{MPa})$ \\
\hline CG & $820 \pm 20$ & $440 \pm 10$ & $520 \pm 15$ & $36 \pm 2$ & $2695 \pm 70$ \\
\hline $\mathrm{CG}+\mathrm{TC}^{*}$ & $900 \pm 15$ & $620 \pm 10$ & $620 \pm 10$ & $31 \pm 2$ & $3150 \pm 75$ \\
\hline UFG & $1310 \pm 20$ & $450 \pm 10$ & $1130 \pm 10$ & $29 \pm 1$ & $3550 \pm 90$ \\
\hline $\mathrm{UFG}+\mathrm{TC}^{*}$ & $1360 \pm 10$ & $530 \pm 15$ & $1200 \pm 15$ & $31 \pm 1$ & $4070 \pm 80$ \\
\hline UFG + upsetting & $1750 \pm 20$ & - & $1410 \pm 20$ & $22 \pm 2$ & $4860 \pm 120$ \\
\hline $\mathrm{UFG}+$ upsetting $+\mathrm{TC}^{*}$ & $1910 \pm 25$ & - & $1550 \pm 15$ & $26 \pm 3$ & $5425 \pm 95$ \\
\hline
\end{tabular}

* Thermal cycling $n=20$

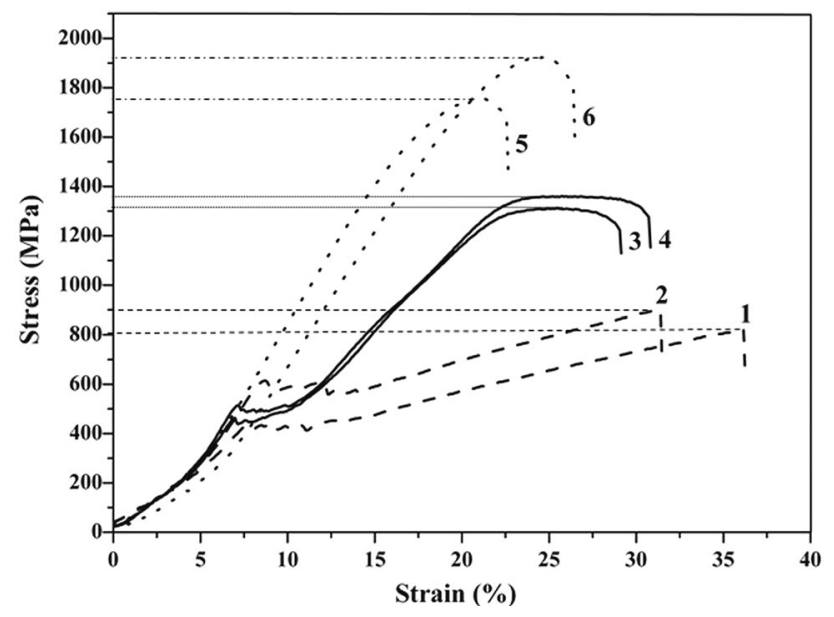

Fig. 6 Stress-strain curves for $\mathrm{Ti}_{49.3} \mathrm{Ni}_{50.7}: 1 \mathrm{CG}, 2 \mathrm{CG}+\mathrm{TC} ; 3$ UFG, 4 UFG + TC; 5 UFG + cold upsetting, 6 UFG + cold upsetting $+\mathrm{TC}$

which indicates the blocking of deformation-induced martensitic transformation. But it is more probable that in the UFG + upsetting alloy, martensitic transformations occur at different loads, and as a consequence, a pseudoyield plateau is not observed on the tensile curve. The absence of phase yield in the deformed TiNi has been noted earlier, in particular in [6]. The thermal cycling is enabled to achieve an increase in the ultimate tensile strength by $200 \mathrm{MPa}$, up to $1960 \mathrm{MPa}$.

Hence, the treatment by thermal cycling of the UFG + upsetting alloy has allowed achieving the highest values of YS, UTS and microhardness in the $\mathrm{Ti}_{49.3} \mathrm{Ni}_{50.7}$ alloy. Here, the elongation in this state remains rather good.

Thus, according to the data from XRD analysis, in the UFG and UFG + upsetting alloys, the dislocation density grows more significantly, as a result of thermal cycling, than that in CG TiNi (Table 1). Consequently, the grain boundaries, the density of which is higher in UFG materials, are additional dislocation generation areas at diffusionless martensitic phase transformations.

On the basis of the obtained data, the following simplest evaluations of the effect of the grain boundaries on dislocation generation during cycles of martensitic transformations can be proposed.

Let us designate the dislocation density growth in the CG material after thermal cycling as $\rho_{\mathrm{CG} \Delta}$, and the dislocation density growth in the UFG material as $\rho_{\mathrm{UFG} \Delta}$.

In the simplest approximation, if one accepts that the grains have the same size and a cubic shape, the area of the intergrain boundaries $(S)$ in a volume unit of a polycrystalline material is given by equation:

$S=3 / D$,

where $D$ is the grain size.

In CG TiNi at $D_{1}$ (the grain size in the CG material) $=50 \mu \mathrm{m}, \quad S=60 \mathrm{~mm}^{2} / \mathrm{mm}^{3} ; \quad$ in UFG TiNi $D_{2}=0.3 \mu \mathrm{m}, S=10^{4} \mathrm{~mm}^{2} / \mathrm{mm}^{3}$.

Let us designate the density of dislocations generated during thermal cycling in the material volume as $\rho_{\Delta \mathrm{V}}$.

It shall be accepted that the density of dislocations generated in the grain boundaries during thermal cycling is directly proportional to the grain area:

$\rho_{\Delta \mathrm{G}}=K_{1} \times S$,

where $K_{1}$ is a certain coefficient and $S$ is the area of the grain boundaries.

Then, the total density of dislocations generated in a volume unit during thermal cycling is as follows:

$\rho_{\Delta}=\rho_{\Delta \mathrm{V}}+K_{1} \times S$.

Therefore, we obtain a system of equations:

$\rho_{\mathrm{CG} \Delta}=\rho_{\Delta 0}+K_{1} \times 3 / D_{1}$,

$\rho_{\mathrm{UFG} \Delta}=\rho_{\Delta 0}+K_{1} \times 3 / D_{2}$.

According to the data from X-ray structural analysis (Table 1), $\rho_{\mathrm{CG} \Delta}=1.07 \times 10^{15} \mathrm{~m}^{-2}, \quad \rho_{\mathrm{UFG} \Delta}=3.71 \times$ $10^{15} \mathrm{~m}^{-2}$.

Using the available experimental data for $\rho_{\mathrm{CG} \Delta}, \rho_{\mathrm{UFG} \Delta}$, $D_{1}$ and $D_{2}$, we shall obtain the following results. 
The density of dislocations generated in a volume unit of TiNi at one hundred cycles or martensitic transformations is $\rho_{\Delta v} \approx 1.0583 \times 10^{15} \mathrm{~m}^{-2}$.

The coefficient reflecting the quantity of dislocations generated by a surface area unit in a material volume unit at 100 cycles of martensitic transformations is $K_{1}=1.8 \times 10^{8} \mathrm{~m}^{-1}$.

\section{Conclusions}

(1) According to TEM and $\mathrm{OM}$, the $\mathrm{Ti}_{49.3} \mathrm{Ni}_{50.7}$ alloy has a structure with a grain size of $50 \mu \mathrm{m}$ in the initial CG state and a grain size of $200 \mathrm{~nm}$ in the UFG state, and the size of structural elements equals $50 \mathrm{~nm}$ in the UFG + upsetting state.

(2) According to TEM, as a result of thermal cycling, an increase in the dislocation density is observed in the vicinity of the grain boundaries and triple junctions in the CG and UFG states.

(3) The calorimetric data show that the thermal cycling results in an increase in the martensitic transformation temperatures, especially $M_{\mathrm{s}}$ and $M_{\mathrm{f}}$.

(4) According to the X-ray analysis, a more significant increment of the dislocation density is observed in the UFG alloy than in the CG one. The highest dislocation density increment is observed as a result of thermal cycling in the UFG + upsetting state-a state with the most refined structure. Thus, the grain boundaries, the density of which is higher in UFG materials, are additional dislocation generation areas at diffusionless martensitic phase transformations.

(5) As a result of thermal cycling, the microhardness of the alloy in the CG and UFG states increases. The highest microhardness increment is observed a result of thermal cycling after UFG + upsetting. As for the UFG + upsetting state, the microhardness grows intensively during the first 20 cycles and is followed by saturation with a further increase in the number of cycles to 100 .

(6) A set of enhanced mechanical properties of the strength, yield stress and ductility is achieved as a result of the combined treatment that includes ECAP, upsetting and thermal cycling.

Acknowledgments The author Anna Churakova acknowledges the support for XRD investigation (the Alexander von Humboldt Foundation through the Group Linkage Project Fokoop-DEU/1052606). The author Dmitry Gunderov acknowledges the support for TEM investigation (the RFBR Project No. 15-08-04784). The author Alexander Lukyanov acknowledges the support for ECAP processing (the Russian Science Foundation through Project No. 14-12-00138).

\section{References}

[1] V. Brailovski, S. Prokoshkin, P. Terriault, F. Trochu, Shape memory alloys: fundamentals, modeling and applications (ETS Publ, Montreal, 2003)

[2] K. Otsuka, C.M. Wayman, Shape memory materials (Cambridge University Press, Cambridge, 1999)

[3] V.N. Khachin, V.G. Pushin, V.V. Kondratiev, Titanium nickelide, structure and properties (Nauka, Moscow, 1992). (in Russian)

[4] S. Miyazaki, T. Imai, Y. Igo, K. Otsuka, Metall. Trans. 17A, 115 (1986)

[5] R.Z. Valiev, Progr. Mater. Sci. 45, 103 (2000)

[6] D.V. Gunderov, A.V. Lukyanov, E.A. Prokofiev, A.R. Kilmametov, V.G. Pushin, R.Z. Valiev, Mater. Sci. Eng. A 503, 75 (2009)

[7] R.Z. Valiev, D.V. Gunderov, E.A. Prokofiev, V.G. Pushin, Y.T. Zhu, Mater. Trans. 49(1), 97 (2008)

[8] D. Gunderov, A. Lukyanov, E. Prokofiev, A. Churakova, V. Pushin, S. Prokoshkin, V. Stolyarov, R. Valiev, Mater. Sci. Forum 738-739, 486 (2013)

[9] Y. Liu, P.G. McCormick, Acta Metall. Mater. 38, 1321 (1990)

[10] A.A. Churakova, D.V. Gunderov, A.V. Lukyanov, YuA Levedev, Lett. Mater. 3, 166 (2013)

[11] Y.X. Tong, F. Chen, B. Guo, B. Tian, L. Li, Y.F. Zheng, D.V. Gunderov, R.Z. Valiev, Mater. Sci. Eng. A 587, 61 (2013)

[12] R.I. Babicheva, K.Y. Mulyukov, Lett. Mater. 1, 156 (2011)

[13] R.I. Babicheva, K.Y. Mulyukov, Appl. Phys. A 116(4), 1857-1865 (2014)

[14] E. Schafler, M. Zehetbauer, T. Ungar, Mater. Sci. Eng. A 319-321, 220 (2001)

[15] T. Ungar, Scr. Mater. 51, 777 (2004)

[16] W. Tang, R. Sandström, Mater. Des. 14(2), 103 (1993)

[17] V.Y. Erofeev, L.A. Monasevich, V.A. Pavskaya, Y.I. Pascal, Fiz. Met. Metalloved. 53(5), 963 (1982). (in Russian) 